\title{
FDI-Local Investment Nexus: Evidence from MENA Region
}

\author{
Nadia Selmi ${ }^{1}$ \\ ${ }^{1}$ Faculté des Sciences Economiques et de Gestion de Tunis, Tunisia \\ Correspondance: Nadia Selmi, Faculté des sciences économiques et de gestion de Tunis, Tunisia. Tel: \\ 216-2477-6655. E-mail: selminadia1@gmail.com
}

Received: March 21, 2016

Accepted: May 10, 2016

Online Published: June 25, 2016

doi:10.5539/ijef.v8n7p123

URL: http://dx.doi.org/10.5539/ijef.v8n7p123

\begin{abstract}
The aim of this article is to measure the interactions likely to occur between Foreign Direct Investment and the local investment in the MENA region. This interaction could take the shape of either a substitution or a complementarity relationship. We have adopted an empirical analysis based on panel data using a sample of 7 countries (Tunisia, Algeria, Morocco, Egypt, Jordan, Lebanon and Syria). We have concluded that the most probable assumption for these countries is the eviction of the local investment projects following the entry of FDI.
\end{abstract}

Keywords: foreign direct investment, mena region, panel data

\section{Introduction}

Debates on foreign direct investments link these flows to a series of benefits for the host country. Indeed, FDI have become a part of an open and efficient international economic system. They are even more desired in developing countries since they are perceived as one of the main catalysts of development factor, a complement of the national investment and a source of financing of the current account deficit. The focus is not so far centered on the direct effects but rather on the technological dimension generated by these investment flows. In fact, for many developing countries which do not enjoy technological advantage, the implantation of a foreign technology appears to be a substitute or a complement to the development of national research activities that these emerging countries are not able to bear the associated expenses.

All these issues have been extensively treated both by the economic literature and the empirical studies leading to rather positive findings regarding the effects of FDI on the economies of the host countries. However, the problem of the relationship between FDI and the local investment has not received as much interest despite its importance. The theoretical studies are not numerous enough and the empirical applications have come to conflicting results. The aim of this paper is then to test empirically, using a sample of 7 countries of the MENA region, the hypothesis according to it FDI contribute to increase the stock of the capital in the host country (Note 1). We have been compelled to reduce the sample size to only 7 countries for data availability reasons. It's worth mentioning that, to the best of our knowledge, there are no studies which have addressed the link between FDI and local investment in this region. We have then targeted the MENA region to try to shed some light on this issue. We will deal with the question of the interaction between FDI and the local investment from the perspective of the gross fixed capital formation. Our purpose is to investigate whether FDI stimulate or discourage the local investment.

\section{The Relationship between FDI and the Local Investment: A Literature Overview}

Despite the numerous studies on FDI, the question of the interaction between these flows and the local investment has not received as much interest. Indeed, theoretical studies are rather few and the empirical applications have come to contradictory findings.

Markusen and Venables (1999) conceptualized this interaction via a partial equilibrium model. They considered two sectors of imperfect competition, bound by an input-output structure. The entrance of the multinationals in the final goods sector have increased competition and crowded out the local firms. However, thanks to the upstream externalities, the foreign companies are stimulating the industrial development of the intermediaries' goods sector. Such complementarities can also generate second order profits for the downstream companies.

Based on the hypothesis that the subsidiaries are created in the upstream sectors, Barrios et al. (2005), developed a similar theoretical model in which they demonstrated that an eviction of the local companies has been noted on 
the short term as a consequence to the decline of the final goods prices. However, this effect is balanced by the stimulation of the request towards the upstream sector in the long term.

The findings of these works are rather optimistic arguing for a stimulating impact of FDI on the long term. Nevertheless, there is a restrictive assumption for the two models dealing with the procurement of intermediate goods from the local market. Actually, some inputs are imported by multinational according to the tariff barriers, to the distance from the countries of origin...

Backer (2003) asserted that many potential entrepreneurs waive up to set up their own businesses preferring working for the account of the foreign companies. What distinguishes the work of Backer is the fact that the eviction impact is led by the employment market instead of the traditional channels of the real and financial markets.

Based on a sample of 36 countries, Agosin and Machado (2005) came to different findings. They asserted that FDI have a crowding out effect for the Latin America countries whereas they seem not to impact the local investment in both Asian and African countries.

Empirically, the question of the effect of FDI on the dynamics of local investment has been marginally addressed in works concerned with economic growth. Borensztein et al. (1998) demonstrated the negative effect of FDI on local investment in Latin America. They asserted that FDI have rather technological externalities than a significant impact on the capital stock. Agosin and Machado (2005) affirm that the crowding out effect was only remarked in developed countries. By calculating a long-term coefficient in order to determine a dynamic effect, Mody and Murshid (2005) have shown that beyond the short-term drawbacks, FDI stimulate the local investment on the long-term .

Through a 22 countries sample of the Eastern Europe, Mileva (2008) have concluded that FDI stimulate the local investment only for the countries renowned by both a weak institutional development and financial systems.

Wang (2010) and Morrissey and Udomkerdmongkol (2012) have found a substitution effect on the local investment. Wang (2010) calculated an additive effect, indicating that even when a foreclosure phenomenon is noted, it certainly disappears after three years of entry of FDI.

Morrissey Udomker Mongkol (2012) approached the issue from the perspective of the political and the economic governance regime. They have established that the relationship between FDI and local investment is as much significant as the economic governance is efficient.

This literature review exposes the great divergence between the different findings which stem from the differences in the characteristics of the sample considered, the utilized variables and the methodology estimation. Our study aims at contributing to the debate and throwing some light upon the issue.

\section{The Research Methodology}

\subsection{The Empirical Specification}

According to the theoretical expectations mentioned above, the process of Investment will be approached through a process of adjustment between the existing capital stock and the stock desired (for this reason, we will introduce the lagged dependent variable). However, we have to take into account the fact that the adjustment is partially achieved because of the liquidity constraints and the access to the funding as well as the temporal adjustments. Taking the works of Mody and Murshid (2005) as our main reference, we will estimate the contribution of FDI in the local investment through an investment function increased by the inclusion of multiple determinants as below:

$$
G F C F_{i t}=f\left(G F C F_{i, t-1}, F D I_{i t}, C_{i t}, G R O W T H_{i, t-1}, R I N T_{i t}, Z_{i t}\right)
$$

GFCF: the Gross fixed capital formation as a percentage of the GDP (the investment rate), the lagged dependent variable $\mathrm{GFCF}_{\mathrm{t}-1}$ considers the persistence of the investment rate. Being a structural component of the economy, we expect the investment to have a strong autoregressive character. The lagged variable $\mathrm{GFCF}_{\mathrm{t}-1}$ highlights the dynamic nature of the relationships and allows- at the same time- the calculation of the long-run coefficients. It allows considering the process of adjustment between the existing capital stock and the one desired.

FDI: the net flows of foreign international investment as a percentage of the GDP. This variable is the proxy used for the real investment made by foreign subsidiaries

$C_{i t}$ : the vector of capital flows other than FDI. We consider here the portfolio investment (PF) and the external debts (ED). Both of these flows are expressed as a percentage of the GDP. We introduced these variables in order to compare the contribution of these types of flows in the determination of the local investment. FDI have 
several theoretical advantages compared with other types of capital. Compared to portfolio investments, FDI, are by definition, long-run commitments. They, therefore, are more stable and react more slowly to the market fluctuations. We also limit the foreign credits to those of long-run, to be more similar to FDI. However, these loans depend much more on the global financial conditions than FDI.

$$
C_{t}=\left(\begin{array}{l}
P F \\
E D
\end{array}\right)
$$

Regarding the investment classic determinants, we include the accelerator investment and the cost of capital. Their expected influence is described below:

GROWTH: Real growth of GDP, delayed by a period to consider the accelerating effect as the future investment is dependent on the growth today.

The real interest rate RINT is a proxy of the cost of capital. We expect a negative correlation with the rate of investment. Although most studies have used the short-term interest rate, we consider more relevant an investment function estimating based on long-run interest rates. To determine the real cost of capital, we deducted the inflation rate from the nominal interest rate.

$Z_{\mathrm{it}}$ : the vector of the control variables including the other determinants of investment. Their introduction is essential to avoid an over-estimation of the interest variables coefficients and also to check the robustness of the results. Inspired by (Mody \& Murshid, 2005; Wang, 2010) works, we have retained the terms of trade, the inflation rate, and the trade openness.

$$
\mathrm{Zt}=\left(\begin{array}{c}
T T \\
I N F \\
T O
\end{array}\right)
$$

TT: the terms of trade as a proxy for the relative price of capital goods imported compared to the export price. We use this variable as a proxy for the relative price of the imported capital goods compared to the export price. Thus, an increase of this ratio shows that exports are relatively more expensive than imports, which leads to a rise in the purchasing power thanks to the export revenues. Regarding the capital goods imports, we expect that an increase in the terms of trade positively impacts the investment. If, however, imports contain mainly consumer goods, the effect on the accumulation of capital remains very low.

INF: the inflation rate in order to measure the economic instability.

TO: the trade openness (calculated as the share of foreign trade in GDP) as an investment incentive factor. We expect that a high degree of open trade encourages investment, especially in exporters sectors.

Our data are extracted from the World Bank Data Base and the International financial statistics Data Base. We referred to the period between1993-2014. The data base was organized in the form of an unbalanced panel with 7 countries observed from the MENA region. The analyzed countries are Tunisia, Algeria, Morocco, Egypt, Jordan, Lebanon and Syria.

To test the substitution/complementary effect of FDI on the local investment, our interest is to compare the coefficient of FDI to 1 . A coefficient of 1 means that the increase in FDI flows will fully be found in the fixed capital formation. A lower coefficient of 1 indicates a negative effect of excluding, while a coefficient greater than 1 is interpreted as a stimulating local investment (Agosin, Machado, Mody, \& Murshid, 2005).

Theoretical models (Markusen \& Venables, 1999) suggest an influence of FDI in two stages, namely an initial effect of substitution, followed by a complementary effect in the long-run. However, in a different context, Aghion and Howitt (1992) have called this effect the "creative destruction". Then, the combination of the effects of FDI on two time horizons allows us to identify four assumptions according to Lahimar (2009), summarized in Table 1 . We note that there is also the possibility that the long-run elasticity would not be significant (or equal to zero). If so, the below assumptions will be reduced to two: substitution or complementarity.

Table 1. Assumptions about the relationship between FDI and the local investment

\begin{tabular}{llll}
\hline & Short-run & Long-run & Effect \\
\hline A1 & $\boldsymbol{\omega}_{\mathrm{sr}}<\mathbf{1}$ & $\boldsymbol{\omega}_{\mathrm{lr}}<\mathbf{1}$ & substitution \\
A2 & $\boldsymbol{\omega}_{\mathrm{sr}}<\mathbf{1}$ & $\boldsymbol{\omega}_{\mathrm{lr}}>\mathbf{1}$ & creative destruction \\
A3 & $\boldsymbol{\omega}_{\mathrm{sr}}>\mathbf{1}$ & $\boldsymbol{\omega}_{\mathrm{lr}}<\mathbf{1}$ & transitory stimulation \\
A4 & $\boldsymbol{\omega}_{\mathrm{sr}}>\mathbf{1}$ & $\boldsymbol{\omega}_{\mathrm{lr}}>\mathbf{1}$ & complementarity \\
\hline
\end{tabular}


In the empirical study, we seek to validate one of these theoretical assumptions. To this end, we will separate analysis based on the horizon time: the short-run and the long-run.

Table 2. The descriptive statistics of the main variables

\begin{tabular}{llllll}
\hline Variable & Obs & Mean & Std. Dev. & Min & Max \\
\hline gfcf & 154 & 24.3196 & 4.9702 & 13.27049 & 38.23645 \\
fdi & 154 & 3.230948 & 4.023175 & -.5984143 & 23.53736 \\
pf & 154 & 1.351676 & 5.070842 & -4.577 & 51.21 \\
ed & 153 & 57.53941 & 40.0603 & 2.49 & 206.85 \\
growth & 154 & 3.633688 & 4.390877 & -21.34 & 13.45978 \\
rint & 154 & 2.860386 & 15.61107 & -121 & 21.56904 \\
tt & 154 & 95.75022 & 24.65782 & 35.47 & 154.68 \\
inf & 154 & 7.029238 & 16.00078 & -3.846154 & 150 \\
to & 154 & 70.18895 & 18.99453 & 38.36 & 133.5 \\
\hline
\end{tabular}

Looking at the Table 2, we note however that the role of FDI in the international flows of capital does not mean quite large relative to the external debts. Aalthough we expect a significant correlation between foreign investment flows and the local investment, it seems at the first glance that the foreign flows still remain below expectations which makes us wonder about the attractiveness of these countries. This could be explained by the effect of the global recession, the socio-political revolution that has erupted in some countries as well the deteriorated security situation and the lack of medium and long term economic visibility.

We note furthermore the high value of the external debts which represent most of the time more than $50 \%$ of the GDP. This reflects the weakness of the evolution of the growth compared to the debt. The governments' indebtedness' have been up in a context marked by an increase in the current budgetary expenditure while that of the other non-financial economic agents relates the persistent investors' skepticism.

\subsection{The Generalized Method of Moment (GMM)}

As a general empirical approach, we have preferred the panel estimation techniques, having many advantages in our case. Indeed, the panel combines the temporal and inter-dimension data and provides more variability. Thus, it has a higher number of degrees of freedom and reduces the collinearity between the explanatory variables (Hsiao, 2003).

The dynamic structure of the equation (1), which results from the presence of the lagged dependent variable $\mathrm{GFCF}_{\mathrm{t}-1}$, raises problems related to the application of the LSE method. We have to note that the introduction of the lagged dependent variable is essential for theoretical reasons, but also because it has the technical advantage to control the risk of the omitted variables. However, in an autoregressive model, so LS estimator than Within, Between or the LS generalized are no longer convergent.

The problem of non-convergence of the LS estimators is explained mainly by two phenomena: The first concern is the biases of the dynamic panel (Nickel, 1981). The variable GFCF $_{\mathrm{i}, \mathrm{t}-1}$ is correlated with the individual fixed effects, giving rise to the autocorrelation of the residues. The second problem appears when certain explanatory variables are endogenous. Since the causality is verified in both directions, the variables could be correlated with the residue violating again the LSE assumptions. An example related to our problematic is the fact that FDI can be attracted by high rates of growth, while remaining themselves a determinant of growth.

The efficient estimation of a dynamic panel is possible using the GMM as it allows to correct the endogeneity of the autoregressive variables and to determine the efficient parameters even in the presence of endogenous explanatory variables. The major advantage over the conventional techniques of instrumental variables is the generation of internal instruments. In practice, the lagged values of the variables are instruments to explain their present values.

It should be mentioned that this method can only correct the endogeneity in the weak sense, but not strong endogeneity. It assumes that some of the explanatory variables are predetermined; they may be affected by both past and present achievements of the dependent variable, but not by its future achievements. We consider relevant to illustrate this hypothesis with an application to the case of FDI. If we consider the FDI flows as a predetermined variable, then we assume that the decisions of foreign investors are not independent of both past and present developments macroeconomic in host countries. This hypothesis is highly plausible indeed. However, 
Carkovic and Levine (2005) argue that this assumption does not exclude foreigners' investors' expectations of the future evolution of the economic situation. It just says that unanticipated future shocks do not affect the current level of FDI.

According to the construction principle of a GMM estimator, here is the equation reflecting a homogeneous dynamic panel with individual fixed effects:

$$
y_{i t}=\lambda_{0}+\lambda_{1}+\alpha y_{i, t-1}+\omega X_{i t}+\varepsilon_{i t}
$$

$y_{i t}$ indicates the dependent variable (GFCF), $X_{i t}$ is the vector of explanatory variables, $\lambda_{0}$ is a constant, $\lambda_{1}$ reflects the individual fixed effects and $\varepsilon_{i t}$ is the residue. The presence of the autoregressive term is justified by the adjustment phenomena, the consideration of the expectations and the hysteresis of the macroeconomics variables.

To eliminate the individual fixed effects, we resort to the differentiation (Arellano $\&$ Bond):

$$
\begin{gathered}
y_{i t}-y_{i, t-1}=\alpha\left(y_{i, t-1}-y_{i, t-2}\right)+\omega\left(X_{i t}-X_{i t-1}\right)+\varepsilon_{i t}-\varepsilon_{i t-1} \\
\Delta y_{i t}=\alpha \Delta y_{i, t-1}+\omega \Delta X_{i t}+\Delta \varepsilon_{i t}
\end{gathered}
$$

Although the differentiation allows to eliminating the individual fixed effects, it does not remove the problem of correlation between the new residual term $\varepsilon_{i t}-\varepsilon_{i t-1}$ and the lagged dependent variable $y_{i t}-y_{i, t-1}$. To remedy to this issue, Arellano and Bond (1991) propose to instrument the differences (of both the lagged dependent variable and the explanatory ones) with the past values of the same variables. This cancels out the Explanatory variables correlation with the current residue but keeps the correlation with the past residue.

Concerning, the number of instruments, Chatelain (2007) have proposed a theoretical procedures for the selection of the appropriate moments. However, taking into account the reduced size of our sample, we are obliged to reduce the number of the instruments. Indeed, multiplying exponentially the number of instruments weakens the power of the Sargan test. Since the lags of one period are, by construction correlated with residues, it is necessary to include delays of at least two periods. We have tested the inclusion of the higher order delays but this makes the estimations unstable and the Sargan test rejects the validity of these instruments. Consequently, we have limited the instruments at the second delay of the dependent variable. We then have instrumented the lagged investment (GFCF) by its own delayed values.

We have also to take into our consideration that the causality between the capital flows and the local investment could interact in both directions. In order to verify the necessity of the instrumentation of these three capital flows, the test of exogeneity of Davidson-MacKinnon (1993) is very useful. Indeed, the test has revealed that these variables are endogenous confirming the existence of a relationship between capital flows and the local investment, and then the necessity to use instrumental variables. Therefore, we have also instrumented these variables (FDI, PF, ED) with their lags.

Table 3. Davidson-MacKinnon test

\begin{tabular}{lcc}
\hline Variables & Davidson-MacKinnon test & P -value \\
\hline FDI & 3,75 & 0,0317 \\
PF & 4,15 & 0,0157 \\
ED & 3,97 & 0,0231 \\
\hline
\end{tabular}

\section{H0: the explanatory variables are exogenous.}

H1: the explanatory variables are endogenous.

The efficiency of the GMM estimator is based on the validation of two hypotheses, the exogeneity of the instruments and the non-correlation of the residuals. The validity of the instruments is checked using Hansen/Sargan tets (built on the assumption that the error term should not be correlated with the set of exogenous variables if the instruments are valid) and the autocorrelation residue is tested by a test proposed by Arellano and Bond (built on the null hypothesis of no autocorrelation and implemented to the differenced residuals). It should be noted that the construction of the differences in equation (3) introduces a first order autocorrelation. Verifying the autocorrelation of the residues is then made from the second order. The test Arellano and Bond AR (2) accepts the null hypothesis of the absence of autocorrelation of second order in the residuals. Sargan test accepts the hypothesis of the validity of the instruments.

Although these estimators are based on the quasi-stationarity, in practice, this assumption tends to be ignored. 
First, the GMM is designed for relatively short time series (in fact this is the main reason for using a panel). Thus, the stationary series can be hardly evaluated. Second, the GMM consists in transforming the original equation in differences, which leads to the disappearance of any possible non-stationary variables trends. Besides, most of the variables used should theoretically be stationary. The investment rate (GFCF/GDP), for example, can record short-term changes, but it is limited in its long-term development. (As a share of income, it could not display a permanent upward or down-ward trend). However, we have tested the stationarity of the series before the estimation. We have used the Levin- Lin-Chu unity root test which has revealed the absence of a non-stationarity problem in our series.

Table 4. The Levin- Lin-Chu unity root test

\begin{tabular}{lll}
\hline & Statistic & p-value \\
\hline Unadjusted $\mathrm{t}$ & -5.6315 & \\
Adjusted $\mathrm{t}^{*}$ & -2.4756 & 0.0067 \\
\hline
\end{tabular}

\section{Empirical Results}

The equation estimated is as follows:

$$
G F C F_{i t}=\alpha G F C F_{i, t-1}+\omega_{1} G R O W T H_{i, t-1}+\omega_{2} F D I_{i t}+\omega_{3} C_{t}++\omega_{4} R I N T_{i t}+\omega_{5} Z_{i t}+v_{i}+\varepsilon_{i t}
$$

With $i=1, \ldots, 7$ represent the country index; $\mathrm{t}=1993 \ldots 2014$ is the considered period; $v_{i}$ are the individual fixed effects with consider to the countries and $\varepsilon_{i t}$ are the idiosyncratic residues.

Table 5. The contribution of FDI on the local investment

\begin{tabular}{|c|c|c|c|c|c|c|}
\hline \multicolumn{7}{|c|}{ Arellano-Bond dynamic panel-data estimation } \\
\hline & gfcf $\mid$ & Coef. & Std. Err. & $\mathrm{z}$ & $\mathrm{P}>|\mathrm{z}|$ & [95\% Conf. Interval] \\
\hline \multicolumn{7}{|l|}{ gfcf $\mid$} \\
\hline L1. | & .6864232 & .0417656 & 16.44 & 0.000 & .6045642 & .7682823 \\
\hline \multicolumn{7}{|l|}{ growth $\mid$} \\
\hline L1. | & .065545 & .0516582 & 1.27 & 0.205 & -.0357032 & .1667932 \\
\hline fdi $\mid$ & .0995535 & .0577648 & 1.72 & 0.087 & -.0147272 & .2138341 \\
\hline $\mathrm{pf} \mid$ & -.023548 & .029266 & -0.80 & 0.421 & -.0809083 & .0338122 \\
\hline ed $\mid$ & -.0124985 & .0056113 & -2.23 & 0.026 & -.0234965 & -.0015005 \\
\hline $\mathrm{tt} \mid$ & -.0408176 & .0092305 & -4.42 & 0.000 & -.0589091 & -.0227262 \\
\hline rint $\mid$ & .1895225 & .0287127 & 6.60 & 0.000 & .1332466 & .2457984 \\
\hline $\inf \mid$ & .1544091 & .0271828 & 5.68 & 0.000 & .1011318 & .2076864 \\
\hline to $\mid$ & .0785955 & .0124745 & 6.30 & 0.000 & .054146 & .103045 \\
\hline cons $\mid$ & 4.681379 & 1.695419 & 2.76 & 0.006 & 1.358418 & 8.00434 \\
\hline \multicolumn{6}{|c|}{$\operatorname{AR}(1)$} & 0.001 \\
\hline \multicolumn{6}{|c|}{$\mathrm{AR}(2)$} & 0.383 \\
\hline \multicolumn{6}{|c|}{ sargan stat } & 0.339 \\
\hline \multicolumn{6}{|c|}{ sargan p-value } & 0.507 \\
\hline
\end{tabular}

We will first discuss the coefficients obtained for the main variables, to focus later on the influence of FDI on the dependent variable. The results confirm that the gross fixed capital formation has a significant structural component $(0<0.05)$. Such a result was expected. It is indeed the engine that drives the wheels of the economic machine by allowing entrepreneurs to raise the necessary resources to produce goods and services. Rapid and sustained growth is promoted by a favorable conjunction in which entrepreneurship and investment induce higher productivity, which in turn allows more investment in the future.

Besides, among the classical determinants, the interest rate is significant $(0<0,05)$ in contrast with the studies incorporating the interest rates which have got inconclusive results (Mody \& Murshid, 2005; Agrawal, 2005; Wang, 2010). This might be due to the specifications of the studied countries. Being developing ones, the interest rate is among the most determinant factors of the investment. Indeed, investors who are often looking for short term profit and prone to herd behavior, are susceptible to a variety of factors including mainly the interest rate. Starting from the fact that the investment function is typically decreasing in relation to interest rates, we have expected a negative correlation between the interest rate and the local investment. The calculated coefficient is 
however positive (0.18). How to interpret such a result? The answer is given by Mankiw (2009) who argues that the relation between the interest rate and the investment depends on the origin of the variation of the interest rate. Studying the relationship between the investment and the interest rate, he concluded that the nature of the correlation deeply depends on the variable that has been modified. When the saving function moves under the effect of the fiscal policy, the correlation between the investment and the interest rate tends to be negative. However, the increase in the investment demand -following to the potential impact of technological innovations or a fiscal investment incentive- raises the interest rate. Hence, the investment volume increases only if the interest rate increases.

The growth rate does not appear to be a stimulating factor $(0.205>0.05)$. This could be explained by the importance of the socio psychological dimension of the investment decision not only linked to a high growth rate but above all to the sustainability of this growth. Indeed, the level of confidence or fear in the future strongly impacts the investors' decision. Under the cumbersome administrative procedures that have always prevailed in the business climate of these countries combined with the little precarious political and security contexts that characterizes most of them (the post revolution transitional period for Tunisia \& Egypt, the war in Syria, the civil war in Lebanon), it is expectable that the growth rate appears as a non-significant variable.

The portfolio investments do not affect the local investment, they display a non-significant coefficient $(0.421>0$, 05). This is mainly due to the fact that the immediate goal of portfolio investors- apart the fact of their weak value- is to get a financial gain, being interested in the distribution of profits rather than their reinvestment. Indeed, their main motivation is the portfolio diversification, not the productive investments. Another explanation is linked to the fact that the financial markets in the region are not enough developed, which limits the potential contribution to the fixed capital formation. Finally, Portfolio investments are more volatile compared to the other international capital flows. Their instability may well harm the productive investments and affect growth prospects.

Regarding the external debts, the situation is much more complicated. Despite a significant coefficient $(0,026)$, the value reflects a negative correlation (-0.012). The foreign loans have been most of the times diverted from their original purpose. Indeed, they have not been intended to finance the investment but rather wasted on financing the administrations of the dictatorships, funding strictly the circles of the power with the aim of monopolizing the countries' economies. All these factors have contributed to degrade the business climate. Resorting to external borrowing to pay salaries of civil servants, fund administration or make investments that do not generate exports have been an economic suicide that has resulted in irreversible budget deficit for all the countries studied.

Regarding the role of foreign direct investment (FDI), a first observation refers to their overall positive contribution to capital accumulation. Thus, an increase in FDI flows of $1 \%$ of the GDP leads to an increase of approximately $0.099 \%$ of the gross fixed capital formation. The value obtained is much smaller than 1 , confirming thus a substitution effect for the local investment. At least in the short term, the increasing competition generated by the entry of the foreign subsidiaries would have a negative effect on the local investment. This effect could reflect a creative destruction case. To valid such an assumption, we have to test the long-term effect.

The Estimations of the model (4), has provided us with a Short-run coefficient of FDI. To validate the theoretical assumptions set in Table 1, we need to determine the effect of the long-run FDI coefficient. Taking into account that the short-term coefficient is much lower than 1, only two assumptions are expected: substitution and creative destruction. The dynamic structure of the equation (4) allows us to calculate the long-run elasticity Investment in FDI flows from the speed of convergence to the equilibrium rate of investment.

$$
\omega_{l r}(F D I)=\frac{\omega_{s r}(F D I)}{1-\propto}
$$

The Significance can be tested using the Wald test to conclude for the true value of the parameter.

Table 7. The Wald test

\begin{tabular}{cc}
\hline The long-run elasticity & 0,317 \\
& $(0,299)$ \\
\hline Wald test & Chi2 $=0,29$ \\
H0: $\alpha_{2}=1$ & $(0,598)$ \\
H1: $\alpha_{2} \neq 1$ & \\
P -value & \\
\hline
\end{tabular}


The long-run elasticity of FDI displays a value of 0,317 (calculated on the base of the estimated coefficients). The first remark is that the coefficient is still smaller than one which shows that the substitution effect is still persistent. However, this value is higher than the short-run coefficient indicating that the crowding out effect of the foreign investment is decreasing. Therefore, if in the short-term there is a substitution relationship (as demonstrated by the less than one FDI coefficient) it tends to reduce in intensity in the long term, yet without turning into a complementarity between FDI and the local investments.

However, according to the Wald test we could not reject the assumption that the long-term coefficient is equal to 1 but we interpret this result very carefully since its significance is quite weak $(0,29)$ as well as the standard deviation which is relatively high $(0,598)$.

We, then, infer that there is certainly a substitution effect of FDI on domestic investment. This effect is decreasing, but its long-term evolution could not lead to complementarity. The Local companies, forced to leave the market because of the competitive pressure and insufficient institutional support, are not fully replaced even after some time. The negative effect on the local investment is likely to occur in the same area, but also in the upstream sector. When we consider the downstream sectors, higher quality inputs can stimulate investment, but this effect is less important and requires more time (especially since the top quality inputs often mean higher supply cost).

It's worth mentioning that since the substitution is the result of the competitive market mechanism, the net gain at the aggregate level will be positive. On the one hand, the consumer will benefit from the better quality of the products offered by the foreign subsidiaries. On the other hand, the high productivity of FDI will accelerate the economic growth.

\section{Conclusion and Recommendations}

The aim of this article is to clarify the relationship between FDI and the gross fixed capital formation in seven countries of the MENA region through a panel data technique. We have concluded that the most plausible assumption for these countries is the eviction of the local investment projects following the entry of FDI.

We wonder, whether the government intervention would be necessary in this regard. The goal of the economic policies is to maximize the internal rate of investment and to avoid the negative effect of substitution.

A liberal opinion would be against a government intervention. However, the elimination of the local companies will increase unemployment. In addition, the economies of these countries would face a long-term denationalization of some sectors.

In this perspective, a selection policy on FDI might be beneficial. The preference should be in a sense that leads to a stimulation of the long-run local investment. The authorities should encourage the establishment of foreign investments in the underdeveloped sectors of the economy avoiding, thus, the areas where there is already a consistent local production.

A last recommendation seeks to encourage export-oriented FDI, provided they respect a minimum local content for their end products. The concrete modalities of the implementation of these measures are likely to fail if it pursues a too restrictive policy. The best solution would- in our opinion- be a combination of a liberal opening foreign investments policy with an incentive system to target certain types of FDI. Thus, even in the case of substitution of local enterprises, governments can use fiscal policy levers to stimulate the reinvestment of funds thus released.

\section{References}

Adams, S. (2009). Foreign direct investment, domestic investment, and economic growth in Sub-Saharan Africa. Journal of Policy Modeling, 31, 939-949. http://dx.doi.org/10.1016/j.jpolmod.2009.03.003

Agosin et al. (2005). Foreign investment in developing countries: Does it crowd in domestic investment? Oxford Development Studies, 3(2), 149-162. http://dx.doi.org/10.1080/13600810500137749

Agosin, M. R. (2008). Is Foreign Investment Always Good for Development? Working Group on Development and Environment in the Americas, Discussion Paper DP09, April-Agosin.

Barrios, S., Görg, H., \& Strobl, E. (2005). Foreign Direct Investment, Competition andIndustrial Development in the Host Country. European Economic Review, 49, 1761-1784. http://dx.doi.org/10.1016/j.euroecorev.2004.05.005

CNUCED. (2013). Renforcer les liens entre l'investissement intérieur et l'investissement étranger direct en Afrique. 
De Backer et al. (2003). Does foreign direct investment crowd out domestic entrepreneurship? Review of Industrial Organization, 22(1), 67-84. http://dx.doi.org/10.1023/A:1022180317898

Hansen, L. (2001). Generalized Method of Moments Estimation: A Time Series Perspective. University of Chicago, Chicago, Illinois, USA.

Horobeț, A., \& Lupu, R. (2006). Foreign Direct Investments as Engines of Growth: An Analysis of FDI Impact on Capital Formation and Productivity. In Identity, Globalization and Universality in Eastern and Central European Economic Area-Evolutions and Involutions in the Modern and Contemporary Period. Experiences, Meanings, Lessons, 1, 154-168.

John, D. S. (1958). The Estimation of Economic Relationships Using Instrumental Variables. Econometrica, 26, 393-415. http://dx.doi.org/10.2307/1907619

Mankiw, N. (2015). Macroeconomics (9th ed.). W. H. Freeman \& Co Ltd.

Manuel, M. R. (2005). Foreign Investment in Developing Countries: Does it Crowd in Domestic Investment? Oxford Development Studies, 33(2), 149-162. http://dx.doi.org/10.1080/13600810500137749

Markusen, J., \& Venables, A. (1999). Foreign Direct Investment as a Catalyst for Industrial Development. NBER Working Paper No. 6241. http://dx.doi.org/10.1016/s0014-2921(98)00048-8

Mileva, E. (2008). The impact of capital flows on domestic investment in transition economies. Working Paper Series 871, European Central Bank.

Misun, J., \& Tomšík, V. (2002). Does foreign direct investment crowd out or crowd in domestic investment? Eastern European Economics, 40(2), 38-56.

Mody, A., \& Murshid, A. P. (2005). Growing up with capital flows. Journal of International Economics, 65, 249-266. http://dx.doi.org/10.1016/j.jinteco.2004.02.003

Morrissey, O., \& Udomkerdmongkol, M. (2012). Governance, private investment and foreign direct investment in developing countries. World Development, 40(3), 437-445. http://dx.doi.org/10.1016/j.worlddev.2011.07.004

OCDE. (2002). L'investissement direct étranger au service du développement, optimiser les avantages minimiser les coûts" rapport de synthèse.

Wang, M. (2010). Foreigh Direct Investment and Domestic Investment in the Host Country: Evidence from Panel Study. Applied Economics, 42, 3771-3721. http://dx.doi.org/10.1080/00036840802314580

\section{Note}

Note 1. The MENA region refers to a large area, from Morocco in northwest Africa to Iran in southwest Asia, which usually includes all countries of the Middle East and North Africa.

\section{Copyrights}

Copyright for this article is retained by the author(s), with first publication rights granted to the journal.

This is an open-access article distributed under the terms and conditions of the Creative Commons Attribution license (http://creativecommons.org/licenses/by/3.0/). 